\title{
The Dynamic Teaching Model of Advanced English Based on Humanism
}

\author{
$\mathrm{Bu}$ Xun \\ Shanghai Normal University Tianhua College, English Department \\ Shanghai, 201815
}

\begin{abstract}
In context of prevailing utilitarianism and examorientation in contemporary college English teaching, the current paper adopts a humanistic perspective claiming that education should be based on learners' self-betterment and aim at their self-actualization. The paper explores the dynamic teaching mode of the course Advanced English and proposes to encourage students to study on their own, to see to their learning needs, to enhance their humanistic quality and create an equal and harmonious learning environment by means of explicit teaching objectives, delicate teaching design, abundant teaching resources and diverse teaching activities.
\end{abstract}

Keywords-Humanism; Self-actualization; Learning needs; Humanistic quality; Teaching environment

\section{CurRent Situation AND PROBlems}

With rapid development of globalization and increasing international economic and cultural exchanges, English teaching in China has entered a period of prosperous development. Nonetheless, affected by various factors, English teaching has always been a little utilitarian and is often considered merely the teaching of language skills. In other words, it is considered sufficient to only acquire listening, speaking, reading, writing and translating skills. For this reason, English students receiving such education are no more than talking parrots [1]. Sometimes, deeply influenced by examoriented education, English teaching aims only to help students get an TEM-4 or TEM-8 certificate or to ensure a better job in the future. As for teaching modes, traditionally, teachers are at its center under which teachers are the authority in class as knowledge initiators while students become passive receivers. Hence, in such boring classes, students feel sleepy while teachers are often the only active participators. In fact, it is earlier clarified in College English Curriculum Requirements issued in 2004 by Ministry of Education of PRC that college English was not only a linguistic course of basic knowledge but also a quality education course aimed to explore more knowledge and learn about the foreign cultures [2]. Therefore, college students are required to not just memorize words, and grasp listening and speaking skills or pass various English tests. They are expected to achieve higher goal, that is, to achieve comprehensive development and self-actualization.

\section{HUMANISM AND TEACHING OF ADVANCED ENGLISH}

Humanistic Psychology can be dated back to 1950s to 1960s with its main representatives A. Maslow, an American social psychologist, and E. Rogers, another American psychologist. Maslow emphasizes on the importance of human's subjective activities and believes that human completes self-actualization through series of subjective activities and learning is a case in point. Rogers proposes meaningful study which attaches great importance to the relation between teaching and study. He argues that students should always play a dominant role in education while all teaching activities should be conducted with students at its core Teachers and students should keep a free, domestic, equal and interactive relation. The teaching objective should be mainly about helping students acquire study methods instead of simply passing on knowledge [3].

The course Advanced English takes on Humanism education thoughts and advocates that teaching activities should be student-centered and proceed from students' selfbetterment with the final task of helping students achieve selfactualization. The curriculum objective is to combine humanistic teaching and teaching of language to improve students' humanistic quality so that they can achieve both basic knowledge and humanities of language through micro and macro education methods, i.e. to dig into the theme and make comparative analysis on cultures by analyzing linguistic phenomena [4]. Through appreciating classics, students can feel the charm of the language, their linguistic aesthetics and cultural sensitivity are improved and they can perform better at identifying problems and use logic and dialectical methods for deep thinking. To put it in detail, in terms of language skills, effective input such as reading classics, text analysis and rhetorical appreciation can promote effective output such as class demonstration, translation and writing among students; in terms of emotional attitudes, cultivating the study mode of autonomous study before class, in-depth thinking after class, speaking out in class and extensive reading after class help students to pick up the habit of reading classics, independent thinking and finding pleasure in discussion; in terms of humanistic quality, the teaching of Advanced English should promote students' logic and analytical qualities, their cultural comparison and analysis abilities, and adapt to students' demand on go-global development and career development, and set its final objective on students' comprehensive and sustainable development. 


\section{HumANISM- BASED DYNAMIC TEACHING ModE}

Humanism-based education advocates that students should be self-motivated in study while teachers can only assist students, set up good environment and inspire their thinking so that they can actively participate in and devoted to study where their potentials will be tapped. In this way, their independent study ability is enhanced and better improvements can be assured. This principle is strongly upheld in the teaching of Advanced English where teaching plans are made with students at the core while teachers the guider. With explicit objectives, delicate designs, abundant resources and diverse activities in teaching, students can thus take initiation in study and accomplish self-development.

\section{A. Make Students Autonomous Learners}

One of the objectives for teaching mode reform is to promote tailor-made study methods and the development of self-study ability among students. The new teaching mode should motivate students and teachers' enthusiasm. Moreover, it should reflect students' subjective role and the teachers' guiding role in the process [5].

Under this principle, before each Advanced English class, key and difficult points of each unit based on the teaching objectives, students' to-do list and various preview materials will be uploaded to the on-line platform, also called the school's curriculum center. Students are required to complete the tasks before each class which guarantees the implementation of Making Students the Subjective Learner. Compared with Elementary and Intermediate English, Advanced English emphasizes more on students' analysis on texts, further discussion on the theme, appreciation of the language and study of writing skills. Accordingly, the preview tasks for students mainly cover several parts. Taking the tasks for unit 4 as an example, students are asked to draw mind maps, do rhetorical analysis, discuss the theme and analyze difficult grammatical points.

Many students say that it is often time-consuming to accomplish the pre-task and the to-do list, and that they need to reflect on some questions for a long time and they even have to further discuss them with classmates. However, it is of great rewards. Everyone come to class with their questions and they are crystal about the key and difficult points of the class; the inclass discussion become more heated and students listen and question with a clear purpose; the students no longer take a passive approach to study but are highly involved and more efficient in study. What's more, the teachers are no longer simply feeding students with knowledge. Instead, they are guiding them to find answers to their own questions and doubts.

\section{B. Integrate Humanistic Spirits and Promote Humanistic Quality}

Kambs holds that the purpose of education is not only to teach students skills but more importantly to promote balanced development in knowledge, emotions and motives based on their willingness and demands to help them develop healthy personality. [3] Another feature of Advanced English is to cultivate students' abilities in language appreciation and literary aesthetics through textual analysis. In the process, their culture sensitivity is strengthened, their humanistic vision is broadened and the humanistic spirits grows in their heart. They are intrigued to read more classics after class. In teaching Advanced English, the following methods are adopted to improve students' language skills and humanistic qualities,

Firstly, students are given reading tasks on classics and visual and audio materials with well-designed questions. They are exposed to various opinions so that they can think critically and make comparative analysis to dig deep in the theme. It not only expands students' reading capacity but also trains their logic and analytical thinking ability. It is known that the cultivation of humanistic spirits requires reading classics. Reading classics enables students to understand people's common experience, helps them cultivate noble values and makes them think what kind of people they want to become and what kind of lives they should have. Influenced by cultural snack effect, students nowadays are often blundering. They can hardly read a whole original classic so that their extracurriculum reading quantity is severely insufficient and their humanistic vision is quite limited. Due to this reason, the author selected famous articles, TED lectures or Harvard Public lectures that share the same or hold opposite opinions with the theme of articles covered in each unit as extra study materials to intrigue students' interest in and urge for knowledge and provoke their enthusiasm on reading. For example, during teaching Unit 2 Bards of the Internet, after a discussion on the influence of technology and the Internet on people's writing behavior, the teacher expanded this theme to the influence of science and technology on human relations, that is, whether the development of science and technology brought people closer or drifted them apart. What's more, a TED lecture was played and students were encouraged to participate in group discussion on their attitudes toward the opinions expressed in the lecture. Reality was called upon and students adopted parallel and vertical comparison to clarify themselves. When teaching Unit 4 with the theme of craze for top schools, the author selected a section of court debate from an American TV episode to ask students to talk about the key features of a paradox and do well-designed exercises on it, thereby greatly intriguing the students and making class much alive. When teaching Unit 6 Being There, the teacher gave a reading assignment on Francis Bacon's Of Travel. Students were encouraged to comparatively analyze the article with the one introduced in the textbook and tell the differences of travel motives introduced in the two articles. When teaching Unit 11 My Wood from E. M. Forster, the teacher revealed four characteristics of humanity, namely stout, avaricious, pseudocreative and selfish. As for extra-curriculum reading, the teacher selected Appetite. Discussion was organized among students on the symbolic meaning in the article to further their understanding on the relationship between desire, possession 
and happiness. Students were inspired to dig deep on the theme and reflect on humanity. Although each student may have different reading capacity and different humanistic vision, they share the same perceptivity toward classics. Teachers plays the role of road sign, offering new perspectives to students and recommending classics to them.

Secondly, students' literary aesthetic ability and translation capacity are improved through linguistic rhetorical appreciation and contrastive analysis on the original and the translated versions. Literary appreciation ability enables students to feel the beauty of words and the charm of the language during reading. Teachers guide students to identify rhetorical devices that are often used in literature, such as simile, metaphor, metonymy, hyperbole and so on, as well as explain to them some use of complex rhetorical devices in Chinese articles, such as euphemism, transferred epithet, analogy, allusion, simulation and so on, which enables students to feel the beauty of these rhetorical devices and their role in strengthening the expressiveness of words. Students can find that even for an article of over 1000 English words, it is also hard to understand because its writer has put so many efforts in organizing the paragraphs and the whole text. Readers have to read through it carefully to understand the intention of the writer and get the underlying charm of the language. As a result, students may in the future learn to use these rhetorical devices in their writing. Reading original works is a way to improve the readers' appreciation ability for articles. By comparative analysis on the original works and the translated ones, as a useful method, can intrigue students' interest. When teaching unit 11, the author found quotation of Shakespeare's 129 in the text and thus looked for the original poem and the translated versions provided by Liang Shiqiu and $\mathrm{Gu}$ Zhengkun respectively. Students then were asked to make comparative analysis on these versions in terms of expressiveness, word choices and rhetorical effects and so on. A junior student in English major has already learned the subject of Translation Theories and Practice and some basic translation skills. Through comparative analysis on the text and the translation, students can put the translation skills into use and feel the difference in terms of language styles, rhetorical devices and translation methods in different translation versions.

\section{Create Equal, Harmonious and Supportive Learning Environment}

According to the humanism-based teaching theory, teachers should fully respect students' creativity during English teaching process, work hard to inspire students' potentials in English study and application, as well as stimulate students to study English with joy, high spirits and creativity. Besides, due to the social property of students, teachers should make efforts to create a cooperative, relaxing, free and supportive study environment among student groups, which is another feature of Advanced English. Diversified interactive activities become the important source of classroom dynamics, including group work before class, mutual comments on in-class demonstration and group competition in after-class tests. To analyze textual structure and the underlying logic, the author divides students into groups for jigsaw reading and then the students draw up their own mind maps. Later they can present their results in class. During the process, students fully take the lead and demonstrate great creativity. They can explore the theme, make analogies, categorize their opinions and explain the logic meaning between each part through various mind maps. They confidently elaborate on their mind maps fluently and flexibly cope with questions and challenges from other groups. Mind maps may seem easy. However, they require comprehension of the text through communication among group members before class. Groups come together to discuss designs for mind maps and draw up difficult points in the text for later consulting the teacher. When modifications are made based on the teacher's advice, students need to prepare for questions and challenges they might get from other groups. All group members work together to get thorough understanding of the abstract and complex text. Each member has their own creative contributions. Together they study and make development, thereby gaining a great sense of achievement. In the whole process, group members work together, different groups interact with each other and students also interacted with their teacher. They interact through comments posted on an on-line forum at the Curriculum Center, written comments given by the teacher, as well as face-to-face mutual comments, asking questions, and competitions between groups in class, which greatly promoting students' motive and interest in study.

\section{Learn Students' Individual Demands}

Humanism-based teaching thoughts also advocate that teachers should proceed from students' individual needs and help them obtain meaningful knowledge they like. Junior college students in English major will take the TEM-8 test in the second semester. They have high demand on preparation for the coming test especially on error correction and translation parts since these two parts are of the higher error rate in real tests. To meet this demand, the teacher sets up translation and error correction workshops during the latter half of the curriculum. The teacher carefully selects exercises that share the same degree of difficulty with TEM- 8 on the two parts for students' assignment after class. In the next class, one group will present its assignment to the whole class. The teacher encourages students to become grammar police to find out typical grammatical errors. Students are asked to propose multiple choices for word use and work out the best version through discussion. The teacher then offers her opinion on such choice based on her professional knowledge of translation theories and practice and later formed a final version as reference. By the end of the semester, all the students have a chance to present to the class their translation work for discussion and get the teacher' $s$ modification and improvement. Different from the traditional teacher-centered translation teaching mode, the translation workshop, popular among students, fully displays students' initiative and enthusiasm. Some students even say, "The translation workshop is fun and interesting, helping us to feel the charm of translation." 


\section{CONCLUSION}

Humanism-based education thoughts offer us valuable theoretical foundations on how to make English class more dynamic, stimulate students' way of thinking, intrigue their interest, improve their participation in class and enhance their sense of achievements. Through dynamic class reforms, teachers should consider themselves as the assistant and company to students and should create a positive study environment and understand students' demands. They should set explicit teaching objectives, work out delicate teaching designs, collect abundant teaching resources and adopt diverse teaching activities to arouse students' interest in and motive for study. It is of vital importance to inspire them to think deeply, intrigue their hunger for expression and enable them to actively participate in study to obtain the sense of achievements. All in all, the essence of teaching lies in helping students realize their ultimate goal. Teaching is a life-long career. It is a question that is worth thinking and exploring how to deliver a good lesson that can equip students with interesting and meaningful knowledge, cultivate sound personality, and achieve selfdevelopment.

\section{ACKNOWLEDGEMENT}

Author Profile: Bu Xun, born in 1981, is an instructor with a Doctor degree. Her research direction is English Teaching, Translation Theories and Practice.

Author Profile: Bu Xun, born in 1981, is an instructor with a Doctor degree. Her research direction is English Teaching, Translation Theories and Practice.

\section{REFERENCES}

[1] Zhang Shaojie. Say No to Foreign Teaching Methods---Survey and Reflection on Current Situation in Foreign Language Teaching in China [J]. Foreign Language in China. 2007. 3

[2] Wu Yuanqiong. \& Huang Hao. Humanism in College English Teaching and Learning [J]. Computer-assisted Foreign Language Education. 2008. (119).

[3] Stevick, E.W. Humanism in Language Teaching [ M]. Great Britain: Oxford University Press. 1990.

[4] Cha Mingjian. Significance of English Major, Professional Awareness and Humanistic Reform [M]. Shanghai Foreign Language Education Press. 2016.5.

[5] Lin Li. \& Wang Zhijiang. Application of Humanistic Activities in English Teaching [M]. Beijing: Capital Normal University Press. 2005. 